
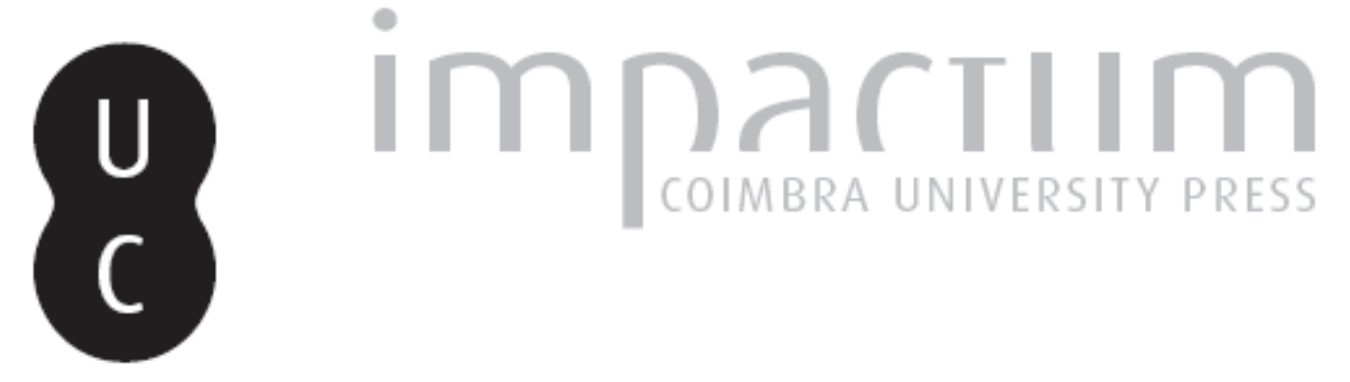

\title{
A mediatização da corrupção política em Portugal: formas, processos e impactos
}

Autor(es): $\quad$ Ferreira, Carlos Filipe Preces

Publicado por: Imprensa da Universidade de Coimbra

URL persistente:

URI:http://hdl.handle.net/10316.2/36962

DOI:

DOI:http://dx.doi.org/10.14195/2183-5462_26_2

Accessed : $\quad$ 26-Apr-2023 06:34:18

A navegação consulta e descarregamento dos títulos inseridos nas Bibliotecas Digitais UC Digitalis, UC Pombalina e UC Impactum, pressupõem a aceitação plena e sem reservas dos Termos e Condições de Uso destas Bibliotecas Digitais, disponíveis em https://digitalis.uc.pt/pt-pt/termos.

Conforme exposto nos referidos Termos e Condições de Uso, o descarregamento de títulos de acesso restrito requer uma licença válida de autorização devendo o utilizador aceder ao(s) documento(s) a partir de um endereço de IP da instituição detentora da supramencionada licença.

Ao utilizador é apenas permitido o descarregamento para uso pessoal, pelo que o emprego do(s) título(s) descarregado(s) para outro fim, designadamente comercial, carece de autorização do respetivo autor ou editor da obra.

Na medida em que todas as obras da UC Digitalis se encontram protegidas pelo Código do Direito de Autor e Direitos Conexos e demais legislação aplicável, toda a cópia, parcial ou total, deste documento, nos casos em que é legalmente admitida, deverá conter ou fazer-se acompanhar por este aviso. 


\section{Media Jornalismo}

\section{CORRUPÇÃO POLÍTICA, MEDIA E DEMOCRACIA}




\title{
A MEDIATIZAÇÃO DA CORRUPÇÃO POLÍTICA EM PORTUGAL: FORMAS, PROCESSOS E IMPACTOS \\ THE MEDIATIZATION OF POLITICAL CORRUPTION IN PORTUGAL: FORMS, PROCESSES AND IMPACTS
}

\section{CARLOS FILIPE PRECES FERREIRA}

CIMJREVISTA@FCSH.UNL.PT

\section{Resumo}

Esta comunicação constata a insuficiência comunicacional do sistema formal de justiça e propõe uma nova estratégia de comunicação que tenha em conta 0 interesse do Estado na realização de uma justiça isenta e independente, 0 interesse do arguido em não ver publicamente revelados factos que podem não vir a ser provados e 0 interesse dos media em informar e dos cidadãos em serem informados. Essa nova estratégia consistiria numa "Plataforma Comum de Comunicação", com base na qual a comunicação seria veiculada oficialmente e por acordo entre os diferentes sujeitos processuais, envolvendo a responsabilização de todos, para todos e com todos.

\author{
Palavras-chave \\ Justiça, Comunicação, Media, Corrupção
}

\begin{abstract}
This paper notes the inefficiency of the communication of the formal justice system and proposes a new communication strategy that takes into account the state's interest in conducting a free and independent justice, the defendant's interest in not seeing publicly disclosed facts that can turn out not to be proved and the interest of the media in informing the citizens. This new strategy would consist of a "Common Communication Platform", based on which communication would be conveyed officially by agreement between the different procedural subjects, involving the responsibility of all for all and with all.
\end{abstract}

KEYWORDS

Justice, Communication, Media, Corruption 


\section{A MEDIATIZAÇÃO DA CORRUPÇÃO POLÍTICA EM PORTUGAL: FORMAS, PROCESSOS E IMPACTOS \\ THE MEDIATIZATION OF POLITICAL CORRUPTION IN PORTUGAL: FORMS, PROCESSES AND IMPACTS}

\section{CARLOS FILIPE PRECES FERREIRA ${ }^{1}$}

CIMJREVISTA@FCSH.UNL.PT

Gostaria de começar por agradecer o amável convite que o Sindicato dos Magistrados do Ministério Público me endereçou para participar nesta Conferência.

Sou Procurador da República, colocado na Instância Central de Comércio de Coimbra, encontrando-me destacado na Comarca de Aveiro para a fase recursiva do processo comum colectivo comummente designado de Face Oculta.

Fui titular do processo "Face Oculta" na sua fase inquérito e assegurei conjuntamente com o Dr. João Marques Vidal a representação do Ministério Público no julgamento.

Acresce que juntamente com o Dr. João Marques Vidal e o Dr. João Melo assegurámos a representação do Ministério Público na fase de Instrução.

Ou seja, acompanhei o processo nas suas diferentes fases.

Aquilo que hoje aqui vos trago resulta da experiência que adquiri por força destas funções e, bem assim, da minha colocação na $1^{\text {a }}$ Secção do DIAP de Aveiro, secção especializada, para além do mais, na investigação da criminalidade económico-financeira.

Independentemente da apresentação que ensaiei sobre o meu percurso profissional, estou aqui - com prazer - a título pessoal pelo que aquilo que direi apenas a mim me compromete.

0 que estamos hoje a discutir é o combate à corrupção no exercício de cargos e funções públicas.

Trata-se de um combate fundamental e decisivo para a democracia e para a identificação dos cidadãos com o regime democrático.

A repressão e dissuasão de fenómeno corruptivos é uma exigência de transparência democrática e é um instrumento indispensável para impedir de facto que o exercício de funções públicas possa ser usado para enriquecer de forma ilegítima e imoral à sombra da inacção das instituições a quem constitucionalmente se acham cometidos poderes/deveres de investigação.

0 terreno da luta contra a corrupção deve ser um terreno de convergência e de conjugação de esforços e não deve ser pretexto para que cada um se limite a marcar o seu território e a tentar espetar a sua bandeirinha para dizer que se distingue dos outros.

Apelando a tal experiência, dir-vos-ei que, hoje por hoje, a investigação dos crimes de corrupção e afins deve assentar num novo paradigma.

1 Procurador-Ajunto do Ministério Público. Comunicação proferida no Centro de Estudos Judiciário com o título "A Mediatização da corrupção política em Portugal: formas processos e impactos", no dia 9 de dezembro de 2014. 
Um modelo de investigação que não se cinge, nem exaura o seu exame ao facto e ao seu autor, procurando analisar a actividade criminosa no seu todo, numa perspectiva não apenas de reconstituição histórica do sucedido, mas de conhecimento em tempo real daquela actividade.

As novas formas de criminalidade associadas ao fenómeno da corrupção não mais se conformam com a mera observação retrospectiva, sustentada no raciocínio dedutivo e na reconstituição do passado.

Uma investigação em cenário de autópsia está, quase sempre, vocacionada para o fracasso.

Urge robustecer a vertente preventiva da investigação criminal, apostando, decisivamente e sem tibiezas, numa forte componente proactiva, antecipando, se possível, a eclosão de práticas corruptivas.

Em todo e qualquer processo, um momento acontece em que a consolidação dos indícios probatórios recolhidos impõem que se promovam e realizem diligências com visibilidade pública, mormente buscas e detenções.

Quando os processos envolvem indivíduos de elevada notoriedade social e/ou política, esta revelação faz nascer dois outros tipos de processos:

0 processo mediático e o processo político.

Nestes casos, o processo judicial funciona como fonte legitimadora daqueles outros processos, alimentando-os, sendo certo que os termos em que o faz são, a mais das vezes, desconformes com a realidade processual.

E porquê?

Por insuficiência comunicacional do sistema formal de justiça que, perante um assunto de relevante interesse público, prefere refugiar-se no espesso manto do segredo de justiça ao invés de revelar o suficiente e o necessário para cortar cerce quaisquer veleidades especulativas na arena mediática.

Os tribunais são o espelho da nossa sociedade, palco onde desfilam as tragédias da vida, assim se justificando a atracção que suscitam junto do público e a mediatização da actividade judicial.

Cabe ao Sistema formal de justiça evitar a deturpação da verdade processual potenciada pelo silêncio a que ele próprio, voluntária e inexplicavelmente, se vota.

Mas, também, e muito, porque dá jeito.

E dá jeito a quem e que propósitos serve?

Às defesas!!!

Como ensinou Jacques Vergès, o apelidado "advogado do diabo", nos processos que visam políticos ou pessoas com elevada notoriedade social, a defesa faz-se não apenas, ou sobretudo, nos tribunais, mas, essencialmente, através dos meios de comunicação social.

Tenha-se presente que as denominadas "violações do segredo de justiça" nunca aproveitam à investigação.

0 único interesse que cogito, por parte da acusação, na revelação de facto processuais radica numa lógica quase mercantilista de auto-promoção.

Para além de espúrio, trata-se de um interesse absolutamente estranho ao sistema formal de justiça.

Dir-me-ão que do ponto de vista do sistema é importante dar a conhecer que, no entanto e parafraseando Galileu Galilei, ele se move. 
Todavia este propósito cumpre-se com o mero conhecimento público do processo.

Não se alcança em que medida um conhecimento mais aprofundado do processo pode significar um reconhecimento maior ou menor da capacidade do sistema.

Mas, mais:

As denominadas "violações do segredo de justiça" têm efeitos devastadores na investigação, os quais podemos sintetizar num bem conhecido acrónimo: "DDT" - Descredibilizar, Descentrar e Torpedear!

Descredibiliza ou desacredita a investigação;

Descentra a discussão, desviando a atenção do objecto do processo, enfatizando-se 0 acessório em favor do essencial;

\section{$\mathrm{E}$}

Torpedeia o processo, veiculando meias verdades ou mentiras convenientes em ordem à deturpação da verdade processual.

Aliás, não será, certamente, por acaso que as denominadas "violações do segredo de justiça" acontecem no momento em que acedem ao processo outros sujeitos processuais, que não os Magistrados, os Órgãos de Polícia Criminal e os funcionários judiciais.

0 processo "Face Oculta" é exemplo assaz impressivo deste axioma.

Com efeito, aquando da emissão de mandados de busca, prevendo que os arguidos a ser constituídos enquanto tal na sequência daquela diligência, pudessem procurar uma estratégia de defesa que passasse pela divulgação pública de partes do objecto do processo, entendemos marcar os mandados de busca com símbolos distintos para cada um dos arguidos, por forma a que fosse possível identificar 0 eventual responsável por aquela publicitação.

Pois bem, o que se previa aconteceu e assim no Telejornal daquele dia 28 de Outubro de 2009, os mandados de busca com os factos que então compunham o objecto do processo foram exibidos.

Acontece que ao sê-lo, quem o fez, não reparou na marca nele aposta e ao exibi-lo para credibilizar a notícia, deu a conhecer o autor da violação do segredo de justiça.

0 arguido veio a ser condenado por Violação do Segredo de Justiça.

Outra circunstância daquele dia 28 de Outubro de 2009 ilustrou como o palco mediático é 0 areópago de excelência eleito pelas defesas para estruturarem as suas estratégias.

Aquando da realização de busca domiciliária a um dos arguidos e havendo ainda um outro mandado ao seu local de trabalho para cumprir, solicitou que primássemos pela discrição na sua execução.

Tratava-se da maior empresa de comunicações do País à data e 0 arguido pretendia não ver maculada a sua imagem e da empresa.

Acedemos ao pedido e entrámos nas instalações recebendo na portaria cartões de convidados.

Fez-se a busca e no seu final, abandonámos as instalações longe de imaginar que o momento em que nos despedíamos do arguido e do seu defensor havia sido fotografado por um importante órgão de comunicação social e já se achava na sua edição on-line.

Apenas, eu, 0 JIC e 0 inspector da PJ que nos acompanhou sabíamos da realização da diligência, para além do arguido e do seu Mandatário. 
Garanto-vos que nenhum daqueles três comunicou com qualquer jornalista em momento prévio à realização da diligência...

Acresce que 0 arguido que pretendia discrição, escassas horas volvidas estava a dar uma entrevista a uma estação de rádio justificando o seu envolvimento no processo.

Como disse, Jacques Vergès: "A politização do processo pode implicar todo um conjunto de estratégias que passam, inclusive, por criar factos apenas imediatamente prejudiciais e apresentar depois, vantajosamente, como vítima deles quem é demandado na justiça como autor de um acto ilícito: passa por desviar a atenção do objecto do processo".

No momento da revelação pública do processo três interesses emergem em notória tensão dialéctica, quais sejam: 0 interesse do Estado na realização de uma justiça isenta e independente, poupada a intromissões de terceiros, a especulações sensacionalistas ou a influências que perturbem a investigação; 0 interesse de evitar que 0 arguido, pelo conhecimento antecipado dos factos e das provas, actue de forma a perturbar o processo, dificultando o aparecimento daqueles e a reunião destas, senão mesmo a subtrair-se à acção da justiça; o interesse do mesmo arguido em não ver publicamente revelados factos que podem não vir a ser provados sem que com que isso se evitem graves prejuízos para a sua reputação e dignidade; 0 interesse da Comunicação Social em informar e dos cidadãos em serem informados.

Importa, por isso, encontrar critérios que permitam conciliar os diferentes interesses em conflito.

0 processo judicial, o processo mediático e o processo político não se interpenetram tripartidamente.

Se o processo judicial é origem e causa do processo mediático e do processo político, já assim não acontece com estes relativamente ao processo judicial.

São dois círculos secantes que se tocam sem se interpenetrarem!

Ou seja, por muito que as estratégias de comunicação da defesa pretendam fazer crer que assim acontece, o certo é que a pretensa contaminação do processo judicial pelo processo mediático e político não se verifica.

Ao processo judicial são, absolutamente, estranhas quaisquer considerações trazida à colacção pelo processo mediático ou político que não conheçam reflexo ou correspondência no processo judicial.

Como dizia Alberto dos Reis "o que não está no processo, não está no Mundo".

Todavia e ainda que assim seja, o processo judicial não pode ignorar a interpenetração recíproca entre o processo mediático e o processo político.

E não 0 esquecendo tem que, na procura da conciliação prática dos interesses da investigação, dos arguidos e da sociedade, corporizada esta pela comunicação social, criar uma política de comunicação eficaz.

Eficaz no sentido de obstar à propagação de inverdades, mentiras ou falsidades em ordem à preservação dos interesses da investigação e dos arguidos.

Assim e para tanto, proponho a criação daquilo que designei por "Plataforma Comum de Comunicação", a qual consistiria no estabelecimento de um perfil de comunicação veiculada oficialmente e por acordo entre os diferentes sujeitos processuais. 
0 Juiz de Instrução Criminal promoveria uma reunião entre o Magistrado do Ministério Público e o Advogado de Defesa no sentido de consensualizarem o quê e em que termos podia ser alvo de divulgação pública.

Findo o segredo interno, os diferentes sujeitos processuais, com a mediação do Juiz de Instrução, definiriam a extensão do segredo de justiça externo.

Responsabilização de todos, para todos e com todos.

Inexistindo acordo, caberia ao Juiz de Instrução Criminal decidir, por despacho irrecorrível, a extensão do segredo de justiça externo.

Uma vez delimitado o segredo de justiça externo, o Presidente da Comarca e 0 Magistrado do Ministério Público Coordenador protagonizariam uma conferência de imprensa revelando os segmentos do objecto do processo contidos nos limites do segredo de justiça externo.

Permitam-me finalizar com um desabafo:

Mais do que leis, mais ou menos perfeitas, o essencial para levar a bom porto esta luta, que deve ser de todos, é Vontade.

Vontade política séria, comprometida com a Constituição e expurgada de interesses particulares mais ou menos secretos;

Vontade de quem investiga para de modo firme, denodado e empenhado actuar de modo solidário, coeso e articulado, na busca de uma investigação isenta, imparcial, despreconceituosa, corajosa e livre de qualquer vinculação ou submissão funcional ao poder executivo;

Vontade do poder judicial para exercer as competências que the são reconhecidas na Lei e na Constituição com independência, equidistância e equidade.

Citando Manuel Alegre direi, a propósito do combate à corrupção que " ...ou o Estado democrático resolve os problemas da República ou alguém os resolverá contra ele". 